\section{IDDF2020-ABS-0150 ADHERENCE TO BEST PRACTICES IN THE DETECTION AND CHARACTERISATION OF PREMALIGNANT UPPER GASTROINTESTINAL LESIONS AMONG ENDOSCOPISTS IN INDIA: A SURVEY}

${ }^{1}$ Deepak Madhu*, ${ }^{2}$ Veeraraghavan Krishnamurthy, ${ }^{2}$ Thirumoorthi Natarajan, ${ }^{3}$ Sundeep Lakhtakia. ${ }^{1}$ Aster MIMS, Calicut (Kozhikode), India; ${ }^{2}$ Cancer Institute (WIA), Adyar, Chennai, India; ${ }^{3}$ Asian Institute of Gastroenterology, Hyderabad, India

\subsection{6/gutjnl-2020-IDDF.96}

Background Given the high morbidity of gastric and esophageal cancers and the absence of population-based screening in India, it is important that all elective Esophago-Gastro-Duodenoscopies (EGDs), irrespective of the primary indication, be viewed as an opportunity to screen for pre-malignant lesions as this will help in early detection of these cancers. With this premise, we aimed to assess the adherence to best practices with regard to the detection of pre-malignant upper gastrointestinal lesions (PMUGIL) among endoscopists in India.

Methods We conducted an electronic survey among endoscopists in India with the primary objective of assessing adherence to best practices (an arbitrary threshold of 90\% adherence was

\begin{tabular}{|c|c|c|c|c|c|}
\hline \multirow[t]{2}{*}{ Best practice } & & \multicolumn{3}{|c|}{ Adherence } & \multirow{2}{*}{$\begin{array}{l}\text { P value } \\
\text { Non- } \\
\text { teaching } \\
\text { centre }\end{array}$} \\
\hline & & & Overall & $\begin{array}{l}\text { Teaching } \\
\text { centre }\end{array}$ & \\
\hline \multicolumn{2}{|l|}{ Adequate time } & $\begin{array}{c}29.76 \% \\
(125 / 420)\end{array}$ & $33.47 \%$ & $25.00 \%$ & 0.06 \\
\hline \multicolumn{2}{|l|}{ Sedation use } & $\begin{array}{r}14.01 \% \\
(59 / 421)\end{array}$ & $13.5 \%$ & $14.67 \%$ & 0.73 \\
\hline \multicolumn{2}{|l|}{ Anti-spasmodic use } & $\begin{array}{r}03.82 \% \\
(16 / 419)\end{array}$ & $03.39 \%$ & $04.37 \%$ & 0.6 \\
\hline \multicolumn{2}{|c|}{ Adequate photo-documentation } & $\begin{array}{c}14.8 \% \\
(62 / 419)\end{array}$ & $12.77 \%$ & $17.39 \%$ & 0.19 \\
\hline \multirow[t]{5}{*}{$\begin{array}{l}\text { Reporting of pre- } \\
\text { malignant lesions }\end{array}$} & $\begin{array}{l}\text { Gastric } \\
\text { Intestinal } \\
\text { Metaplasia }\end{array}$ & $\begin{array}{c}41.99 \% \\
(173 / 412)\end{array}$ & $38.96 \%$ & $45.86 \%$ & 0.16 \\
\hline & $\begin{array}{l}\text { Gastric } \\
\text { Atrophy }\end{array}$ & $\begin{array}{c}70.39 \% \\
(290 / 412)\end{array}$ & $70.56 \%$ & $70.17 \%$ & 0.93 \\
\hline & Barrett's & $\begin{array}{c}90.78 \% \\
(374 / 412)\end{array}$ & $90.91 \%$ & $90.61 \%$ & 0.92 \\
\hline & $\begin{array}{l}\text { Esophageal } \\
\text { mucosal } \\
\text { lesions }\end{array}$ & $\begin{array}{c}77.43 \% \\
(319 / 412)\end{array}$ & $76.62 \%$ & $78.45 \%$ & 0.66 \\
\hline & $\begin{array}{l}\text { Gastric } \\
\text { mucosal } \\
\text { lesions }\end{array}$ & $\begin{array}{c}86.65 \% \\
(357 / 412)\end{array}$ & $85.71 \%$ & $87.85 \%$ & 0.53 \\
\hline \multirow[t]{5}{*}{$\begin{array}{l}\text { Use of Image Enhanced } \\
\text { Endoscopy (IEE) Criteria }\end{array}$} & EGGIM & $\begin{array}{r}08.79 \% \\
(35 / 398)\end{array}$ & $10.81 \%$ & $06.25 \%$ & 0.11 \\
\hline & $\begin{array}{l}\text { Kimura - } \\
\text { Takemoto }\end{array}$ & $\begin{array}{r}11.31 \% \\
(45 / 398)\end{array}$ & $13.06 \%$ & $09.09 \%$ & 0.21 \\
\hline & BING & $\begin{array}{r}21.86 \% \\
(87 / 398)\end{array}$ & $26.58 \%$ & $15.91 \%$ & 0.01 \\
\hline & PREDICT & $\begin{array}{r}03.27 \% \\
(13 / 398)\end{array}$ & $03.15 \%$ & $03.41 \%$ & 0.89 \\
\hline & $\mathrm{IPCL}$ & $\begin{array}{c}36.43 \% \\
(145 / 398)\end{array}$ & $41.89 \%$ & $29.55 \%$ & 0.01 \\
\hline
\end{tabular}

considered adequate) and with the secondary objectives of assessing the adequacy of training, availability of appropriate facilities and differences between teaching and non-teaching centers.

Results Among 422 eligible responses, the adherence to best practices assessed were lower than the set threshold in all except one metric (table 1) in both teaching centers and nonteaching centers. Only $58.5 \%$ of endoscopists had received training in the detection of PMUGIL. Appropriate Image Enhanced Endoscopy (IEE) facilities for evaluating PMUGIL were available to only $58.05 \%$ of surveyed endoscopists.

Conclusions Strategies to improve detection of PMUGIL should be directed at improving best practice adherence, training and endoscopy equipment.

\section{IDDF2020-ABS-0152 APPLICATION OF DIGITAL PATHOLOGY IN DIAGNOSIS OF TISSUE-BASED HELICOBACTER PYLORI INFECTION}

Chun Keung Wong*. Biomedical Scientist and Chemist, Hong Kong

\subsection{6/gutjnl-2020-IDDF.97}

Background Recent advances in pathology service ensure the provision of quality and safety patient management of infectious diseases. Introduction of advanced equipment in the laboratory better manages the growing need for patient service in the hospitals. Helicobacter pylori is a common gastric pathogen that may cause gastritis, peptic ulcer and gastric cancer diseases. Digital pathology provides excellent supports to tissue-based research, clinical diagnosis and patient management of infection caused by this common stomach germ. This study focuses on the applications of digital pathology in clinical pathology, aiming at investigating the recent advances for optimizing the quality of pathology service and providing better patient management of Helicobacter pylori infections.

Methods A qualitative study with literature review has been performed on the application of digital pathology in the diagnosis of Helicobacter pylori infection for gastric biopsies. An inductive qualitative study had been performed, which involved the literature review of websites based documents and case study reflective notes, etc. Conclusions were then made based on the findings and patterns identified in the study. The study used 'maximum variation sample' for eliminating the factor of demographic variable affecting the result of the study.

Results Results showed that digital pathology allows digital slide sharing and remote analysis in pathology networks. Diagnosis of Helicobacter pylori infection is facilitated through utilizing powerful computer interface supported with feature-rich viewing software. It allowed better patient management through the prompt and correct choice of drug. Timely adoption of digital pathology is thus vital for providing high-quality pathology service in the hospital.

Conclusions With the application of whole slide imaging, digital pathology is a recent advanced technology employed in the clinical pathology laboratory worldwide. The scanning of conventional glass slides into digital slides facilitates both diagnosis and public health research. It allows accurate diagnosis with readily retrievable archival images to compare with the latest microscopic finding. Digital pathology utilizes high performance web-based infrastructure to support the diagnosis of tissue-based Helicobacter pylori infection. Whole slide scans stored in the cloud-based server with data security measures 
allow data sharing between hospitals and facilitates laboratory workflow, patient management and enhances public health research.

\section{IDDF2020-ABS-0153 LATISSIMUS DORSI FLAP TO REPAIR A RECURRENT EVENTRATION OF THE DIAPHRAGM: A NOVEL TECHNIQUE}

${ }^{1}$ Veerabhadra Radhakrishna*, ${ }^{2}$ Chittur Narendra Radhakrishnan. ${ }^{1}$ Bangalore Medical College and Research Institute, India; ${ }^{2}$ Manipal Hospitals, India

\subsection{6/gutjin-2020-IDDF.98}

Background Eventration of the diaphragm is a rare congenital anomaly characterized by an abnormal elevation of a part or

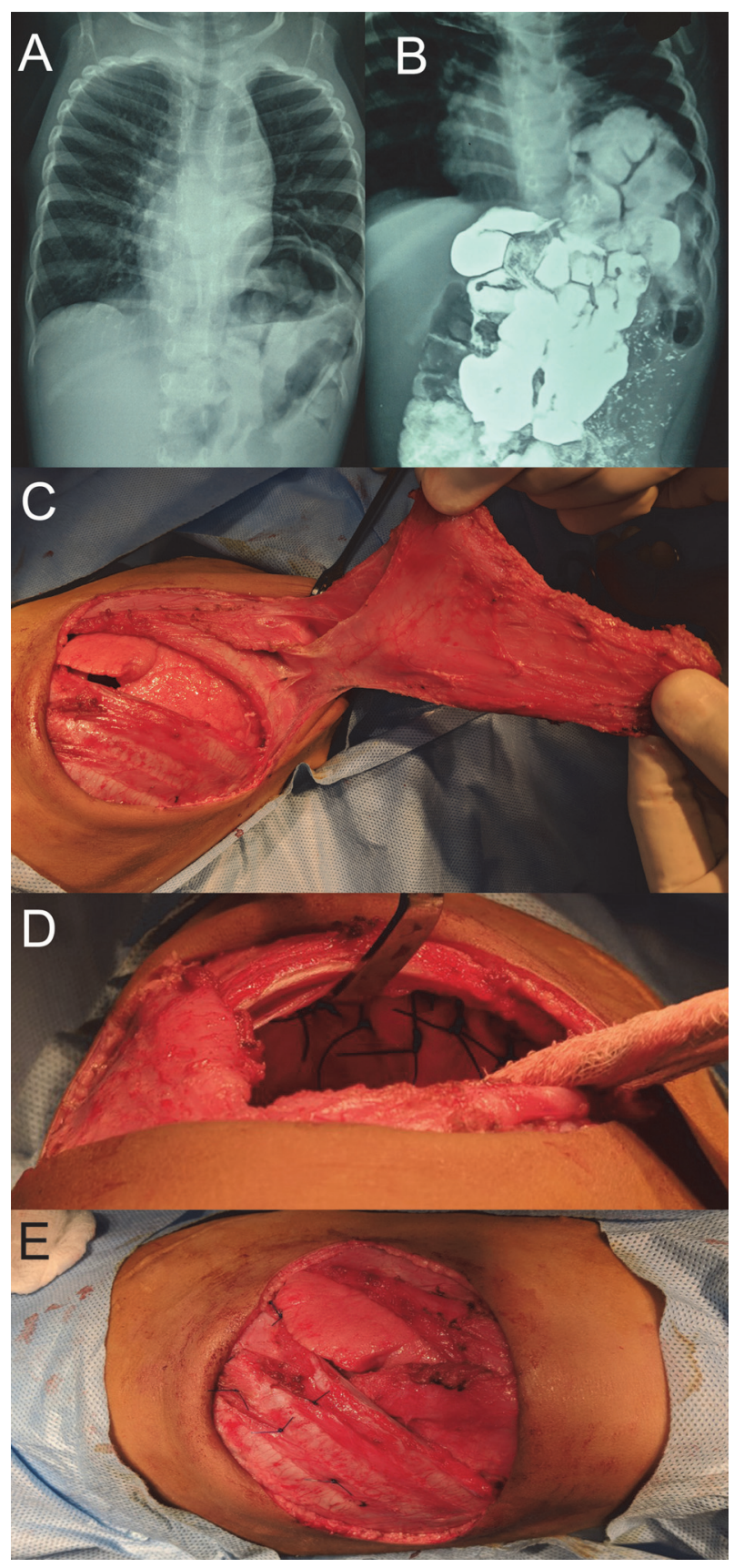

Abstract IDDF2020-ABS-0153 Figure 1 whole of the hemidiaphragm. Surgical repair is indicated in symptomatic patients and the care should always be taken to overcorrect to prevent a recurrence. As the eventrated part of the diaphragm is diffusely replaced by fibroelastic tissue, there is a high tendency to recur even after the repair of eventration. The literature on the recurrence of eventration and its repair is scarce. Here, we report a case of recurrent eventration of the diaphragm in an infant managed by latissimus dorsi flap.

Methods An 11-month-old-female infant with a past history of surgery for left-sided eventration of the diaphragm presented with recurrent lower respiratory tract infections.

On examination, she was active, alert, and pink. Her heart rate was 110 beats a minute, respiratory rate was 52 breaths per minute, and the oxygen saturation was $91 \%$ in room air. Air entry was reduced over the left lung areas. An abdominal examination was normal, except for a left subcostal scar.

Plain X-ray chest showed a recurrence of eventration (figure 1A). An upper gastrointestinal contrast study revealed the stomach and splenic flexure occupying the eventration and no evidence of gastro-oesophageal reflux (figure 1B). She was planned for plication repair with latissimus dorsi flap reinforcement.

Results Intraoperatively, a left-sided latissimus dorsi flap was identified, dissected, and safeguarded (figure 1C). Thoracotomy was done in the 5 th intercostal space. The eventrated diaphragm was plicated (figure 1D) and reinforced with left latissimus dorsi flap (figure 1E).

The follow-up was uneventful. She was thriving well at two years follow-up. To the best of our knowledge, this is the first case where latissimus dorsi flap has been used as dynamic recruitment between the thoracic and the abdominal cavity for managing recurrent diaphragmatic eventration.

Conclusions The latissimus dorsi flap reinforcement is a novel and reliable technique to treat recurrent eventration of the diaphragm. The inherent motor tone of latissimus dorsi resists the intraabdominal pressure and prevents the recurrence of diaphragmatic eventration.

\section{IDDF2020-ABS-0154 FACTORS ASSOCIATED WITH FAILED NON-OPERATIVE REDUCTION OF INTUSSUSCEPTION IN CHILDREN}

Veerabhadra Radhakrishna, Bahubali Deepak Gadgade. Bangalore Medical College and Research Institute, India

\subsection{6/gutjnl-2020-IDDF.99}

Background The non-operative method of reduction is the gold standard treatment for intussusception in children. The successful non-operative reduction of intussusception carries less morbidity and mortality, but the literature on the risk factors for failed intussusception reduction is scarce. Hence a study was conducted to evaluate the factors associated with the failure of non-operative reduction of intussusception in children.

Methods A retrospective study was conducted in a Paediatric Surgery hospital, which included children admitted with intussusception between November 2013 and February 2020.

Results A total of 106 (67\%) children underwent pneumatic reduction. Eighty-nine (84\%) children had a successful 